\title{
Dissolved organic matter and arsenic removal with coupled chitosan/UF operation
}

\author{
Cheng-Fang Lin ${ }^{a}$, Chung-Hsin Wu ${ }^{b, *}$, Hsien-Tin Lai ${ }^{a}$ \\ ${ }^{a}$ Graduate Institute of Environmental Engineering, National Taiwan University, Taipei, Taiwan, ROC \\ ${ }^{\mathrm{b}}$ Department of Environmental Engineering, Da-Yeh University, 112, Shan-Jiau Road, Da-Tsuen, Chang-Hua, Taiwan, ROC
}

Received 16 April 2007; received in revised form 24 August 2007; accepted 4 September 2007

\begin{abstract}
Long time uptake arsenic will cause cancers and blackfoot disease. There are still several million people suffering from drinking arsenic contaminated water. This work studied the performance of coupled chitosan/UF for arsenic removal and the influence of dissolved organic matter on arsenic removal with UF operation. Humic acid representing dissolved organic matter was fractionated into five groups of molecular sizes by gel filtration chromatography. Arsenic rejection by UF under the experimental condition is only $10 \%$. In the presence of humic compounds, the arsenic removal of $22 \%$ is obtained. DOM with apparent molecular weight $>35,000 \mathrm{Da}$ is the principle component responsible for chelating arsenic and thereafter being rejected by UF membrane. The combined interactions of humic compounds, chitosan, and arsenic enable a $65 \%$ arsenic rejection by UF. The results presented here enable our understanding of the complicated mechanisms involved in chitosan/UF/DOM/arsenic system.
\end{abstract}

(C) 2007 Elsevier B.V. All rights reserved.

Keywords: Arsenate; Ultrafiltration; Chitosan; Dissolved organic matter; Gel filtration chromatography

\section{Introduction}

In early 1960s, cases of blackfoot disease were disclosed in south-western area of Taiwan [1]. Early studies on blackfoot disease showed there is a fairly intimate relationship between black skin symptoms on toes and fingers, and arsenic in drinking waters [2-6]. The arsenic concentrations of drinking water samples range from 10 to $1800 \mathrm{~g} / \mathrm{L}$ with mean value of $500 \mathrm{~g} / \mathrm{L}$ and half of the samples analyzed have concentrations between 400 and $700 \mathrm{~g} / \mathrm{L}$ [7]. However, researchers conducting animal tests with arsenic were unable to generate similar blackfoot syndrome [8-10]. By further examining the constitutes of well waters, $\mathrm{Lu}$ et al. [11] found that there are dissolved organic matters with total organic carbon of $18 \mathrm{mg} / \mathrm{L}$ that will emit fluorescence on exposure to ultraviolet (UV) light. These dissolved organic matters (DOM) are humic materials and are complexed with As [12-14]. The blackfoot disease symptoms were successfully generated using animal tests with the isolated and concentrated humic/arsenic materials in well water [15]. Currently, usage of well water in this endemic area of blackfoot disease is prohibited.

\footnotetext{
* Corresponding author. Fax: +886 55334958.

E-mail address: chunghsinwu@yahoo.com.tw (C.-H. Wu).
}

However, in north-eastern Taiwan, there are some regions where people still use groundwater containing some $600 \mathrm{~g} / \mathrm{L}$ arsenic [16]. Furthermore, it is estimated that over 40 millions people are exposed to high health risk of arsenic in Bengal (India), Bangladesh, and Vietnam [17].

Both arsenic and DOM are concerned materials to remove in water supply industry. DOM is not a regulated contaminant under safe drinking water act. However, DOM serves as precursors for generation of disinfection-by-products (DBPs) [18]. Arsenic can cause liver, lung, kidney, and bladder cancers; additionally, arsenic has acute and chronic effects on dermal and nervous system. The United States of America (USA) is very concerned with arsenic in drinking water and the Safe Drinking Water Act requires Environmental Protection Agency (EPA) to revise the existing 50 parts per billion (ppb) standards for arsenic in drinking water. EPA is implementing a $10 \mathrm{ppb}$ standard for arsenic.

The current technologies for arsenic removal are grouped to four categories: coagulation, adsorptive process, ion exchange, and membrane separation [19]. Coagulation with alum and ferric salts is able to achieve $90 \%$ of arsenic removal efficiency and $\mathrm{As}(\mathrm{V})$ is more easily to be removed than $\mathrm{As}(\mathrm{III})$ [19-22]. Adsorptive processes using activated aluminum and iron-coated sand were reviewed by USEPA [19]. Both acti- 
vated aluminum and iron-coated sand provide good removal performance. However, there are many factors affecting the performance of adsorptive process including system $\mathrm{pH}$, presence of competing ions, oxidation state of arsenic, and empty bed contact time, etc., [23]. Ion exchange has been applied to remove trace toxic ions from waters. The performance in terms of removal efficiency and capacity in bed volumes are greatly dependent on water quality, dissolved solids, water $\mathrm{pH}$, resin type, and presence of competing ions. With different resins, a variation from 300 to 60,000 bed volumes of water treated before regeneration is reported [19]. Beside operational instability, ion exchange process may face resin regeneration and spent resins treatment problems. Membrane processes have received considerable attention in water purification industry because of the low membrane costs, simplicity of operation and development of high flux membranes [24]. The ability of membrane technologies on rejection of arsenic from source waters is quite dependent on type of membrane used, source water characteristics, and operation conditions. Microfiltration (MF) alone is certainly unable to exert any removing capability because of the big pore size unless arsenic is in particulate forms. However, coagulation assisted MF may able to achieve some extent of arsenic removal efficiency. Ultrafiltration (UF) process is generally employed to remove DOM with large molecular size for reducing DBPs formation. Due to the large membrane molecular weight cutoff (MWCO) size, UF is not so capable of removing dissolved arsenic. The recent surveyed figures by EPA revealed that total arsenic removal ranged from $<1 \%$ to $63 \%$ using UF with MWCO 8000 and $10,000 \mathrm{Da}$ [19]. It is very interesting to note that arsenic removal efficiency raises to near $70 \%$ for groundwater containing high dissolved organic carbon (DOC) and 30\% for groundwater containing low DOC, based on pilot study using UF with MWCO $8000 \mathrm{Da}$; and the rejection rate of $\mathrm{As}(\mathrm{V})$ is higher than As(III) [19]. Brandhuber and Amy [25] studied arsenic removal by a charged UF and also investigated the influences of membrane operating conditions and water quality on arsenic rejection. The arsenic rejection rate varies from $0 \%$ to $80 \%$, depending significantly on operating conditions, presence of anions, and natural organic matters. Sulfate exerts more influence on arsenic removal than monovalent anions. The rest two membranes' technologies, reverse osmosis (RO) and nanofiltration (NF) because of the small pore size, are superior to $\mathrm{UF}$ on arsenic rejection efficiency. A very reliable $\mathrm{As}(\mathrm{V})$ rejection of 85-90\% was reported [19]; however, As(III) is easy to permeate through NF membrane with only $12 \%$ retained for the same UF system.

Both NF and RO are reliable arsenic removal processes. However, the very small pore size makes $\mathrm{NF}$ and $\mathrm{RO}$ are prone to fouling than low pressure-driven UF. Besides high flux rate is attainable, UF process only requires low energy expenditure and maintain. Indeed, several integrated processes have been developed to promote the efficiency of UF while maintaining the high flux of permeates. Membrane surface coating by ferric iron [26] and coupled UF/activated carbon processes [27-30] are very successfully examples. In addition to the above noted integrated systems for DOM removal, Juang and Shiau [31] employed chitosan-enhanced UF process for divalent metals removal. Their results showed the metals removal was enhanced by $6-10$ times via the addition of chitosan.

As we noted above, UF process is not very promising for arsenic removal, but UF process provides several operating advantages. By coupling with an adsorbent, the overall treatment performance could be enhanced. Chitosan is a natural polymer derived from deaceylation of chitin. Chitosan is an environmental friendly adsorbent but has not been applied widely in water purification industry. Therefore, in this work, we studied the coupled UF/chitosan for arsenic removal using low MWCO polysulfone hollow fiber membrane. Additionally, the performance of UF and UF/chitosan for the removal of humic acid was also investigated. The experiments include (i) humic acid and arsenic removal by UF/chitosan operation, and (ii) complexation between fractionated humic acid and arsenic. This work provides some insight into the interactions between fractionated NOM and arsenic as well as the interactions among UF, DOM and chitosan.

\section{Experimental materials and methods}

\subsection{Feed solutions}

Humic acid solution, arsenic solution, and synthetic well water containing humic acid and arsenic solution were used as the feed water. The commercial humic acid (sodium salt, Aldrich) $1 \mathrm{~g} / \mathrm{L}$ was dissolved in Milli-Q deionized water and then filtered through $0.45 \mu \mathrm{m}$ membrane filter. Arsenic solution was prepared by first oven drying $\mathrm{As}_{2} \mathrm{O}_{5} \cdot x \mathrm{H}_{2} \mathrm{O}$ (MW 229.84, Aldrich) at $102-103^{\circ} \mathrm{C}$ for $30 \mathrm{~min}$ before dissolving $1.553 \mathrm{~g}$ in $1 \mathrm{~L}$ in Milli-Q deionized water. Both humic acid solution and arsenic solution were quantitatively calibrated before making synthetic well water. Sixty-two milliliters of humic acid solution and $1.0 \mathrm{~mL}$ arsenic solution were mixed to make $1 \mathrm{~L}$ synthetic well water consisting TOC $18.5 \mathrm{mg} / \mathrm{L}$ and arsenic concentration $1.0 \mathrm{mg} / \mathrm{L}$ and solution $\mathrm{pH}$ was adjusted to $7.6 \pm 0.1$. The concentrations of humic acid and arsenic designated here were to simulate "Degree 3" well water of the epidemic blackfoot disease area [32].

\subsection{Chitosan}

Chitosan is a deacetylated product of chitin, which is the second abundant biopolymer next to cellulose in earth. The deacetylation process is to generate amino groups, which are capable of reacting with environmental contaminants. The degree of deactylation is normally in between $65 \%$ and $90 \%$ and the product is referred as chitosan if total nitrogen weighs $>7 \%$ [33]. Four chitosans are obtained from Green-Chitosan Science and Technology Co., Taiwan. One is in powdered form and referrers to as "CP". The other three chitosans (referred to as $\mathrm{CB}$, \#5 and \#6) are in granular bead form with diameter less than $0.5 \mathrm{~mm}$. The size of these three chitosan beads is in the order of $\# 5>\# 6>$ CB. 


\subsection{Adsorption experiments}

Batch adsorption experiments were conducted to evaluate the adsorption efficiency of chitosan for humic acid and arsenic. Adsorption kinetic experiments were used to determine the time required for adsorption of humic acid and arsenic on chitosan to reach equilibrium. Water containing $18.5 \mathrm{mg} \mathrm{TOC} / \mathrm{L}$ humic acid was in contact with $800 \mathrm{mg} / \mathrm{L}$ chitosan for $120 \mathrm{~h}$. Water samples were taken at predetermined intervals to measure the fraction of humic acid adsorption. Same procedure was carried out for arsenic $(1 \mathrm{mg} / \mathrm{L})$ and chitosan $(4 \mathrm{~g} / \mathrm{L})$ system. In adsorption isotherm experiments of humic acid, chitosan dosages of 0 , $200,400,600,800$ and $1000 \mathrm{mg} / \mathrm{L}$ were in contact with $18.5 \mathrm{mg}$ TOC/L humic acid solution at $25^{\circ} \mathrm{C}$ for 24 -h using a reciprocal shaker at $200 \mathrm{rpm}$. At the end of the 24 -h period, the solution was filtered using $0.45 \mu \mathrm{m}$ filter membrane and the filtrate was analyzed with TOC analyzer. In adsorption isotherm experiments of arsenic, chitosan dosages of $0,1,2,3,4$, and $5 \mathrm{~g} / \mathrm{L}$ were in reaction with $1.0 \mathrm{mg} / \mathrm{L}$ arsenic solution at $25^{\circ} \mathrm{C}$ for $24-\mathrm{h}$ using a reciprocal shaker at $200 \mathrm{rpm}$. At the end of the $24-\mathrm{h}$ period, the solution was filtered using $0.45 \mu \mathrm{m}$ filter membrane and the filtrate was analyzed with inductively coupled plasma (ICP) for arsenic.

\subsection{Fractionation of humic acid}

Humic acid solution was subjected to gel filtration chromatography (GFC) for fractionating DOM into various apparent molecular weight sizes. The Sephadex G-75 gel (Pharmacia) was employed as a packing material. Blue dextran (Pharmacia) was used to calculate the bulk void volume of the column (C 16/70, Pharmacia). Polyethylene glycol (PEG, Merck) with molecular weights of $1500,6000,20,000$, and 35,000 Da were used to calibrate the column apparent molecular weight. The eluent was collected in a fraction collector and five fractions were thus obtained for subsequent experiments and analysis.

\subsection{UF operation}

The UF membrane used in this work was single hollow fiber module. The membrane material is made by polysulfone and is hydrophobic in nature with negatively charged surface $(A / G$ Technology, USA). The physical characteristics of a single hollow fiber are: length $29 \mathrm{~cm}$, area $90 \mathrm{~cm}^{2}$, and MWCO 10,000 Da. Cross-flow mode was operated in the UF system by recirculating only the concentrate to simulate an actual UF plant configuration. For chitosan-pretreatment system, the solution was first treated with chitosan $(800 \mathrm{mg} / \mathrm{L}$ for humic acid solution, $4 \mathrm{~g} / \mathrm{L}$ for arsenic solution, $4.8 \mathrm{~g} / \mathrm{L}$ for synthetic well water) for $72-\mathrm{h}$, and the filtrate (through No. 42 Whatman filter paper) was fed to the UF system. The UF system was operated at a transmembrane pressure of approximate 20 psi.

\subsection{Analyses}

Filtered ( $0.45 \mu \mathrm{m}$ membrane) humic acid solution was quantified with total organic carbon analyzer (O.I. model 700)

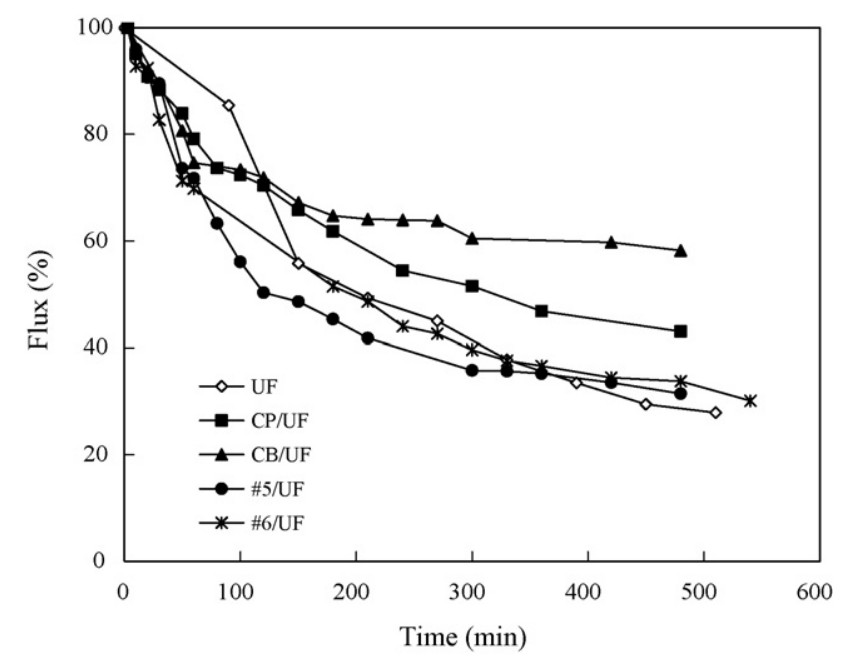

Fig. 1. Permeate flux of UF operation using humic acid solution and pretreatment with four chitosans (coupled chitosan/UF process). The chitosan dosage is $800 \mathrm{mg} / \mathrm{L}$.

for TOC concentration. Arsenic concentration was analyzed with inductively coupled plasma-atomic emission spectrometry (Jobin Yvon JY-24) according to the method of Taiwan national environmental laboratory (NIEA M104.00T). The fluorescence intensity of humic acid was analyzed by spectrofluorometer (Hitachi F-4500). The excitation wavelength was set at $225 \mathrm{~nm}$ and scanning wavelength was from 400 to $600 \mathrm{~nm}$. The emission at $452 \mathrm{~nm}$ was recorded as fluorescence intensity. Membrane specimens were also prepared for morphological observation using a Hitachi S520 scanning electron microscope (SEM).

\section{Results and discussion}

UF membrane process is vulnerable to fouling with natural organic matter (NOM) solutions. An initial permeate flux of $108 \mathrm{~L} /\left(\mathrm{m}^{2} \mathrm{~h}\right)$ is obtained, and flux declines to $30 \%$ of the initial value in about $6 \mathrm{~h}$ when a TOC $18.5 \mathrm{mg} / \mathrm{L}$ humic acid solution was fed into the UF membrane. It has been studied extensively that association (and also accumulation) of NOM on membrane surface is the major reason of fouling and thus the flux decline [29,30,34,35]. The kinetic experiments of humic acid and arsenic showed that 24 and 72-h are enough for DOM/chitosan and As/chitosan to reach pseudo-equilibrium state. The adsorption isotherm experiments results showed the adsorption plateau is equivalent to a sorption density of $7 \mathrm{mg}$ TOC/g chitosan. This adsorption density of chitosan is much less than $45 \mathrm{mg}$ TOC/g using powdered activated carbon [36]. The maximum sorption density of As/chitosan system is $0.1 \mathrm{mg} / \mathrm{g}$. Chitosan is a natural biopolymer and imposes no expenses on earth resources; however, the use of chitosan for NOM and arsenic removal is not very technically attractive.

The effects of chitosan pre-treatment on UF permeate flux is shown in Fig. 1. Without chitosan pretreatment, UF permeate flux declines to $40 \%$ of the initial flux in $5 \mathrm{~h}$ and to $30 \%$ in $8 \mathrm{~h}$. Chitosan CB exerts the best effects on maintaining permeate flux. Chitosan \#5 and \#6 exhibit no improvement on reducing membrane fouling. Firstly, we examine the NOM removal 
Table 1

Removal of humic acid with chitosans

\begin{tabular}{|c|c|c|c|}
\hline Chitosan & Initial TOC ${ }^{\mathrm{a}}(\mathrm{mg} / \mathrm{L})$ & Final TOC $(\mathrm{mg} / \mathrm{L})$ & Removal efficiency $(\%)$ \\
\hline \#5 & 20.63 & 28.94 & -40.28 \\
\hline \#6 & 19.67 & 13.18 & 32.99 \\
\hline $\mathrm{CP}$ & 18.40 & 12.95 & 29.58 \\
\hline
\end{tabular}

a There is some variation on the humic acid concentrations prepared in the experiments.

Table 2

Removal of humic acid with UF and chitosan/UF

\begin{tabular}{llcc}
\hline Process & Initial TOC $^{\mathrm{a}}(\mathrm{mg} / \mathrm{L})$ & Final TOC $(\mathrm{mg} / \mathrm{L})$ & Removal efficiency (\%) \\
\hline UF & 18.28 & 5.52 & 69.79 \\
\#5/UF & 20.63 & $19.08^{\mathrm{b}}$ & 7.51 \\
\#6/UF & 19.67 & 3.89 & 80.22 \\
CP/UF & 18.40 & 3.54 & 80.73 \\
\hline
\end{tabular}

a There is some variation on the humic acid concentrations prepared in the experiments.

b Chitosan \#5 continues to dissolve and adds more TOC in solution.

by chitosans. Table 1 shows the removal of humic acid with three chitosans. The average removal efficiency is around $30 \%$ except chitosan \#5. The increase in final TOC concentration is because of chitosan dissolution after we carried out blank tests for $216 \mathrm{~h}$. The effects of chitosan CP on inhibiting flux decline may be attributed to either adsorption of DOC foulants or reduction in total TOC concentration. A humic acid concentration of $13 \mathrm{mg} / \mathrm{L}$ equivalent to the chitosan $\mathrm{CP}$ pre-adsorption solution was subjected to UF operation. The chitosan CP as well as \#6 pre-adsorption systems generate worse flux decline than the original humic acid solution with same TOC concentrations. Therefore, it is justified to state that both the DOC characteristics and concentration affect permeate flux and membrane fouling.

The coupled chitosan/UF process provides better TOC removal efficiency in comparison to using chitosan adsorption alone. Table 2 shows the removal of TOC in UF and chitosan/UF systems. Both chitosan power (CP) and chitosan bead (\#6) do enhance TOC removal compared to UF alone by about $10 \%$ except the chitosan \#5 which provides only $7.51 \%$ DOC removal efficiency.

To determine why humic acid (in terms of dissolved TOC) removal of chitosan \#5 coupled with a UF system was only $7.51 \%$, which was considerably worse than that obtained with a UF system alone $(69.79 \%)$, the GFC technique was employed for fractionating the molecular sizes of dissolved organic matter pretreated with chitosan \#5 without UF permeation. The molecular size distributions of chitosan \#5 pretreated with dissolved organic matter are as follows: 66\% DOC in 1500-6000 Da; $11 \%$ DOC in 6000-20,000 Da; and, 23\% DOC in 20,000-35,000 Da. For comparison, the molecular size distributions of chitosan \#6 pretreated dissolved organic matters are as follows: 4\% DOC in 1500-6000 Da; 22\% DOC in 6000-20,000 Da; and, 74\% DOC in 20,000-35,000 Da. The molecular size distribution of chitosan pretreated with dissolved organic matter demonstrates that more small DOC exists in the chitosan \#5 system than in the chitosan \#6 system. Those small DOC was probably dissolved
Table 3

Removal of arsenic with UF and four types of chitosan

\begin{tabular}{llll}
\hline Process & Initial As ${ }^{\mathrm{a}}(\mathrm{mg} / \mathrm{L})$ & Final As $(\mathrm{mg} / \mathrm{L})$ & Removal efficiency $(\%)$ \\
\hline UF & 1.29 & 1.17 & 9.34 \\
CP & 1.01 & 1.00 & 1.15 \\
CB & 1.39 & 1.04 & 25.24 \\
$\# 5$ & 1.33 & 0.91 & 31.16 \\
$\# 6$ & 1.33 & 0.90 & 32.20
\end{tabular}

a There is some variation on the arsenic concentrations prepared in the experiments.

Table 4

Effects of arsenic on quenching fluorescence intensity of humic acid

\begin{tabular}{llll}
\hline AMW & $\begin{array}{l}\text { Fluorescence } \\
\text { intensity of humic } \\
\text { acid }\end{array}$ & $\begin{array}{l}\text { Fluorescence } \\
\text { intensity of humic } \\
\text { acid and As }\end{array}$ & $\begin{array}{l}\text { Relative } \\
\text { quenched } \\
\text { intensity (\%) }\end{array}$ \\
\hline$>35,000$ & 6808 & 4362 & 35.9 \\
$20,000-35,000$ & 4972 & 4352 & 12.4 \\
$6000-20,000$ & 5000 & 4220 & 15.6 \\
$1500-6000$ & 5607 & 5600 & 0.1 \\
$<1500$ & 7197 & 5289 & 26.5 \\
\hline
\end{tabular}

compounds from chitosan \#5, but not originating from humic acid, and sufficiently small to penetrate through the UF membrane. This supposition explains why TOC removal efficiency in the chitosan \#5/UF system is only $7.5 \%$.

The arsenic removal efficiency of UF and four types of chitosan are presented in Table 3 . UF and chitosan $\mathrm{CP}$ is unable to remove arsenic effectively. Arsenic removal by chitosan $\mathrm{CB}$, \#5, and \#6 ranges from $25 \%$ to $32 \%$. Chitosan $\mathrm{CP}$ exhibits good performance for DOM removal, however, it is the worst for arsenic removal. The ability of chitosan for arsenic removal is probably dependent on degree of deacetylation, which produces amino groups as coordination sites for chelating ions. Despite of several studies employed chitosan as adsorbent to remove metals [37-39]; however, no reference reported the use of chitosan on arsenic removal. In this study, we were proposing arsenic is rejected in chitosan/UF system as an entity of either humic-As or chitosan-As complexes or in chitosan-humic-As forms. At this stage, we investigated the association between arsenic and humic acid by spectrofluoroscopy as arsenic is able to quench the fluorescence intensity emitted by humic materials due to the complexing reactions. The relative quenched intensity is summarized in Table 4. It is evident that complexation of arsenic to humic compounds does reduce the emitted fluorescence intensity on $450 \mathrm{~nm}$ except the AMW 1500-6000 Da group. It can also be shown that arsenic is tending to be associated with larger humic compounds as a $36 \%$ quenched intensity was observed. By this mechanism, arsenic can be rejected by UF operation through filtration of humic/arsenic complexes and possibly other mechanisms of membrane surface adsorption as well $[40,41]$.

In order to enhance arsenic removal by chitosan-humicarsenic interaction, a chitosan dosage of $4.8 \mathrm{~g} / \mathrm{L}$ was used in the $\mathrm{UF} / \mathrm{chitosan}$ operation of synthetic well water. It is very interesting to note that there is a significant improvement in preventing membrane fouling by this operation and chitosan dosage. As it can be seen in Fig. 2, a pretreatment process with chitosan 


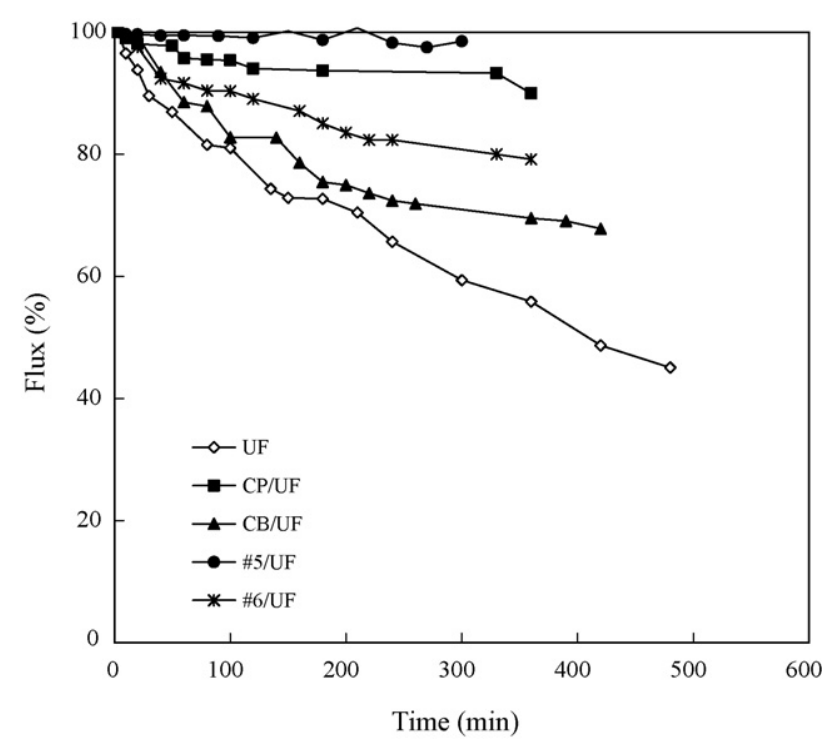

Fig. 2. Permeate flux of UF operation using synthetic well water and pretreatment with four chitosans (coupled chitosan/UF process). The chitosan dosage is $4.8 \mathrm{~g} / \mathrm{L}$.

Table 5

TOC removal from synthetic well water by UF and chitosan/UF process

\begin{tabular}{llcl}
\hline Process & Initial TOC $^{\mathrm{a}}(\mathrm{mg} / \mathrm{L})$ & Final TOC $(\mathrm{mg} / \mathrm{L})$ & Removal efficiency (\%) \\
\hline UF & 18.08 & 6.18 & 65.82 \\
$\# 5 / \mathrm{UF}$ & 18.50 & $15.94^{\mathrm{b}}$ & 13.83 \\
\#6/UF & 18.50 & 4.09 & 77.88 \\
$\mathrm{CP} / \mathrm{UF}$ & 20.47 & 4.56 & 77.72 \\
$\mathrm{CB} / \mathrm{UF}$ & 18.50 & 15.08 & 18.49
\end{tabular}

a There is some variation on the humic acid concentrations prepared in the experiments.

b Chitosan \#5 continues to dissolve and adds more TOC in solution.

\#5 (before experiment, chitosan \#5 was washed using deionized water for 20 cycles with $12 \mathrm{~h}$ per cycle) does not cause permeate flux decline severely. A pretreatment with chitosan $\mathrm{CP}$ also maintain an $85 \%$ of the initial flux for $6 \mathrm{~h}$ operation. All of the chitosan pretreatment performs a better flux production than the UF alone where the flux is $60 \%$ less. Indeed, the yellow colored synthetic well water becomes transparent after treated with chitosan \#5. The TOC removal efficiency of these UF and chitosan/UF coupled process are presented in Table 5. Chitosan \#5/UF operation does not generate low TOC permeate, however, this operation does not cause much flux decline. It is highly likely that most of the foulants contributed from humic acid are removed by chitosan \#5 and the DOCs in solution probably originated from chitosan \#5.

Tables 6 and 7 show the arsenic removal by chitosan adsorption and by chitosan/UF, respectively. The previous results indicated that UF is not very capable of rejecting arsenic by this negatively charged polysulfone membrane. A $22 \%$ rejection rate was obtained in this study using UF alone. Brandhuber and Amy [25] reported an averaged $75 \%$ arsenic rejection rate of $50 \mathrm{~g} / \mathrm{L}$ solution at $6.4 \times 10^{-6}$ to $1.8 \times 10^{-5} \mathrm{~m} / \mathrm{s}$ permeate flux with charged ultrafiltration membrane. This arsenic rejection changes from $20 \%$ to $80 \%$ as function of flow recovery. Sub-
Table 6

Arsenic removal from synthetic well water by chitosan adsorption

\begin{tabular}{llll}
\hline Chitosan $^{\mathrm{a}}$ & Initial As (mg/L) & Final As (mg/L) & Removal efficiency (\%) \\
\hline \#5 & 1.03 & 0.43 & 58.49 \\
$\# 6$ & 1.03 & 0.55 & 46.54 \\
CP & 1.03 & 0.87 & 15.56 \\
CB & 1.03 & 0.61 & 40.63 \\
\hline
\end{tabular}

a The chitosan dosage is $4.8 \mathrm{~g} / \mathrm{L}$.

Table 7

Arsenic removal from synthetic well water by chitosan/UF process

\begin{tabular}{llll}
\hline Process & Initial As (mg/L) & Final As (mg/L) & Removal efficiency (\%) \\
\hline \#5/UF & 1.03 & 0.36 & 64.82 \\
$\# 6 / \mathrm{UF}$ & 1.03 & 0.41 & 59.65 \\
$\mathrm{CP} / \mathrm{UF}$ & 1.03 & 0.77 & 24.75 \\
$\mathrm{CB} / \mathrm{UF}$ & 1.03 & 0.55 & 46.33 \\
\hline
\end{tabular}

${ }^{*}$ The chitosan dosage is $4.8 \mathrm{~g} / \mathrm{L}$.

stantially, concentration polarization might play some extend of role in arsenic rejection. Based on their results, arsenic removal using UF operation can be increased by varying the recovery. With chitosan pretreatment and UF operation, arsenic removal of near $65 \%$ is achievable using chitosan \#5. However, the TOC rejection is low. But still the permeate flux can be sustained.

UF membrane because of the loose pore structure is unable to provide effective arsenic removal by filtration. Arsenic rejection is achieved by electrostatic repulsion of the charged membrane and possible association with surface. Presence of NOM enhances arsenic removal by two ways: (i) formation of NOM gel layer on membrane surface, which enhance arsenic filtration and (ii) formation of humic/arsenic complexes, which is rejected by membrane. The former mechanism can be visualized qualitatively by SEM photo of the UF membrane. Permeate flux decline during UF operation is largely due to gel layer formation on the membrane surface and, possibly, dissolved organic matter clogging membrane pores. A gel layer seldom forms on clean membrane; thus, one can easily examine permeate flux to ensure that no filtration resistance existed during operation. Examining SEM images of the origin of membrane and used membranes to differentiate clean from fouled membranes is reasonable (Fig. 3). Fig. 3 shows SEM graphs of the clean membrane, humic acid deposited sample, chitosan \#5 pretreatment samples, and chitosan CP pretreatment sample. Fig. 3a shows the clean UF membrane in which one could visualize irregular membrane pores. When fed a humic acid solution, the surface of the UF membrane became covered with dissolved organic matter (Fig. 3b). This covered dissolved organic matter is referred to as a gel layer, which is the main reason for permeate flux decline. In Fig. $3 \mathrm{c}$ and $\mathrm{d}$, the thickness of the gel layer is less obvious than that in Fig. 3b, suggesting that pretreatment with chitosan \#5 and chitosan CP reduces gel layer formation as one still could visualize the original membrane pores in these two systems. The temporal variation of permeate flux (Fig. 2) also supports this hypothesis as minimal flux decline was measured. Therefore, applying chitosan decreases gel layer formation. 

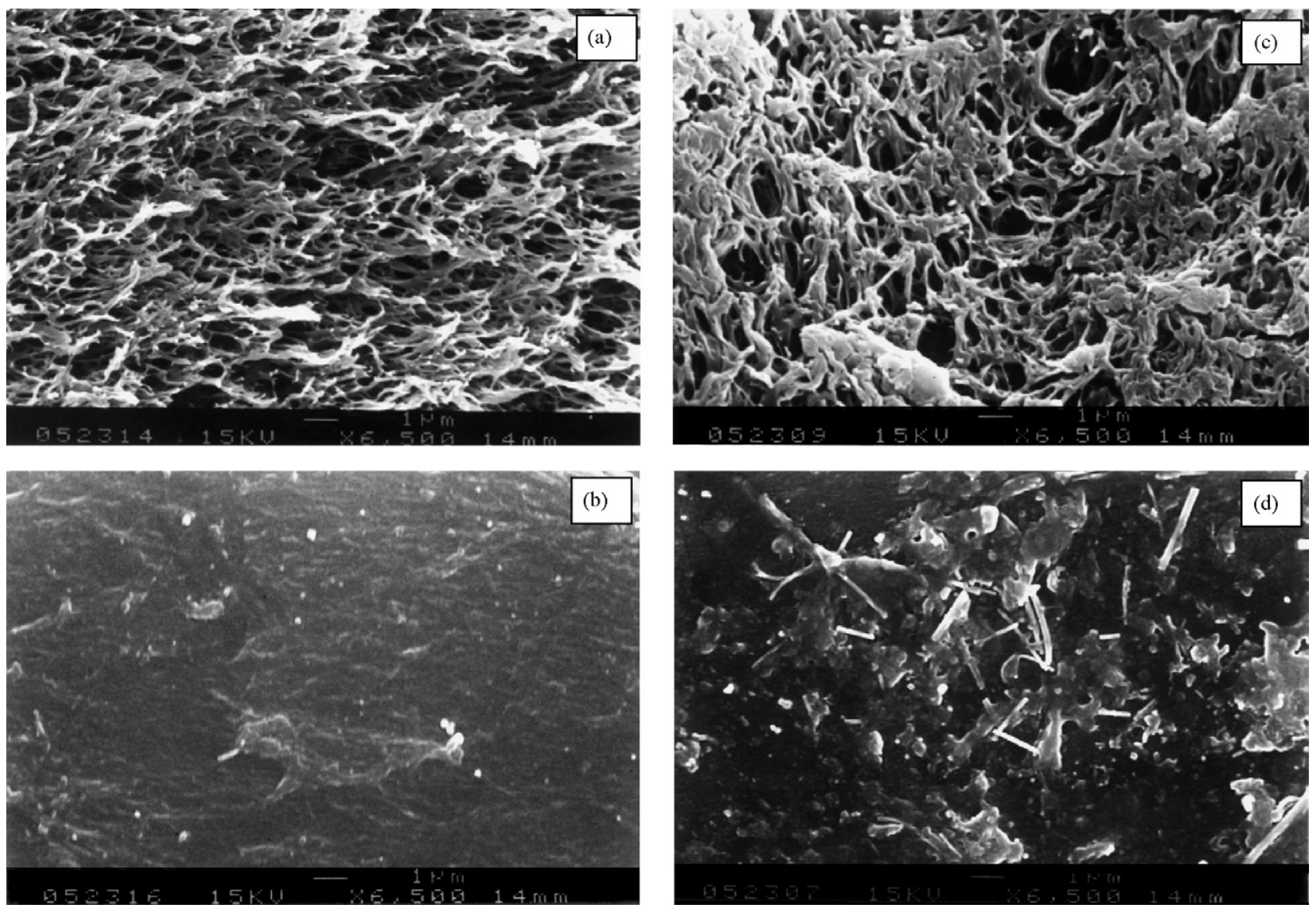

Fig. 3. SEM graphs of various samples. (a) Original UF membrane. (b) UF membrane feed with humic acid solution. (c) UF membrane feed with chitosan \#5 pretreated humic acid solution. (d) UF membrane feed with chitosan CP pretreated humic acid solution.

\section{Conclusion}

There are several million people in the risk of drinking arsenic contaminated water nowadays. UF membrane is a very promising technology in water purification industry. However, the performance of UF for arsenic removal depends on operation parameters as well as water characteristics. In this work, the coupled chitosan/UF process was used for DOM and arsenic removal. Furthermore, the influence of humic acid on arsenic removal by UF operation was investigated extensively. Chitosan, an environmental friendly biopolymer, has weak affinity for arsenic but a good adsorbent for DOM. Chitosan pretreatment of humic acid solution by adsorption can retard membrane fouling effectively. Arsenic rejection by UF under the experimental condition is only $10 \%$. At the presence of humic compounds, the arsenic removal of $22 \%$ is obtained. DOM with apparent molecular weight $>35,000 \mathrm{Da}$ is the principle component responsible for chelating arsenic and thereafter being rejected by UF membrane. The combined interactions of humic compounds, chitosan, and arsenic enable a $65 \%$ arsenic rejection by UF. UF may not be an excellent method for both DOM and arsenic rejection because of the loose pore structure. With understanding of the water characteristics and with use of proper adsorbent in coupled process, UF not only can provide cost-effective water flux but also an acceptable rejection performance.

\section{Acknowledgements}

The authors would like to thank the National Science Council of the Republic of China for financially supporting this research under Contract No. NSC 92-2211-E-002-026.

\section{References}

[1] C.J. Chen, Y.C. Chuang, T.M. Lin, H.Y. Wu, Malignant neoplasms among residents of a blackfoot disease endemic area in Taiwan: high arsenic well water and cancer, Cancer Res. 45 (1985) 5895-5899.

[2] W.P. Tseng, W.Y. Chen, J.L. Sung, J.S. Chen, A clinical study of blackfoot disease in Taiwan: an endemic peripherial vascular disease, Mem. Coll. Med. Natl. Taiwan Univ. 7 (1961) 1-8.

[3] R.O. Blackwell, T.H. Yang, I. Ai, Preliminary report on arsenic levels in water and food from the endemic blackfoot, J. Formosan Med. Assoc. 60 (1961) 1139-1140.

[4] K.P. Chen, H.Y. Wu, Epidemiologic studies on blackfoot disease. 2. A study of source of drinking water in relation to the disease, J. Formosan Med. Assoc. 61 (1962) 611-618.

[5] K.P. Chen, H.Y. Wu, T.C. Wu, Epidemiologic study on blackfoot disease in Taiwan. III. Physicochemical characteristics of drinking in endemic blackfoot disease area, Mem. Coll. Med. Natl. Taiwan Univ. 8 (1962) 115-129.

[6] S. Yeh, Studies on endemic chronic arsenism in southwest coast of Taiwan, Report, Institute of Pathology, National Taiwan University 14 (1963) 1-23.

[7] T.L. Kuo, Arsenic content of artesian well water in endemic area of chronic arsenic poisoning, Report, Institute of Pathology, National Taiwan University 20 (1968) 7-13. 
[8] W.Y. Chen, E.P. Lien, Experimental studies on the drinking water of blackfoot endemic areas. 1. Studies on the changes of the limbs of experimental rats receiving repeated injections of drinking water of blackfoot endemic area, J. Formosan Med. Assoc. 62 (1963) 794-805.

[9] W.Y. Chen, T.S. Yen, Experimental studies on the drinking water of blackfoot endemic areas. 2. Studies on the effects of drinking water of blackfoot endemic area on peripheral vascular perfusion of the hind limbs of frogs, J. Fromosan Med. Assoc. 63 (1964) 150-158.

[10] W.Y. Chen, W.P. Tseng, Experimental studies on the drinking water of blackfoot endemic areas. 3. Skin test with drinking water of blackfoot endemic areas, J. Formosan Med. Assoc. 63 (1964) 298-305.

[11] F.J. Lu, C.K. Yang, K.H. Ling, Physicochemical characteristics of drinking water in blackfoot endemic areas in Chia-I and Tainan Hsiens, J. Formosan Med. Assoc. 74 (1975) 596-605.

[12] F.J. Lu, M.H. Tsai, K.H. Ling, Studies on fluorescent compounds in drinking water of blackfoot disease endemic areas. 2. Isolation and identification of fluorescent compounds, J. Formosan Med. Assoc. 70 (1977) 209-217.

[13] F.J. Lu, M.H. Tsai, K.H. Ling, Studies on fluorescent compounds in drinking water of blackfoot disease endemic areas. 3. Isolation and identification of fluorescent compounds, J. Formosan Med. Assoc. 77 (1978) 68-76.

[14] F.J. Lu, S.C. Tsai, J.Y. Chen, Studies on natural toxicants occurring in artesian well water of blackfoot disease endemic exposed to fluorescent compounds, J. Chin. Biochem. Soc. 9 (1980) 49-54.

[15] F.J. Lu, T.M. Lin, Fluorescent compounds in drinking water of blackfoot disease endemic areas: animal experimental model, J. Formosan Med. Assoc. 85 (1986) 352-358.

[16] K.H. Hsu, J.R. Froines, C.J. Chen, Studies of arsenic ingestion from drinking water in northeastern Taiwan: chemical speciation and urinsary metabolities, in: C.O. Abernathy, R.L. Calderon, W.R. Chapman (Eds.), Arsenic Exposure and Health Effects, Chapman Hall, London, 1997, pp. 190-209.

[17] P.L. Smedley, D.G. Kinniburgh, A review of the source, behaviour, and distribution of arsenic in natural waters, Appl. Geochem. 17 (2002) 517-568.

[18] S.W. Krasner, J.P. Croue, J. Buffle, E.M. Perdue, Three approaches for characterizing NOM, J. Am. Water Works Assoc. 88 (1996) 66-79.

[19] USEPA, Technologies and costs for removal of arsenic from drinking water, EPA 815-P-01-001, 1999.

[20] M.A. Edwards, Chemistry of arsenic removal during coagulation and Fe-Mn oxidation, J. Am. Water Works Assoc. 86 (1994) 64-77.

[21] J.G. Hering, P. Chen, J.A. Wilkie, M. Elimelech, S. Liang, Arsenic removal by ferric chloride, J. Am. Water Works Assoc. 88 (1996) 155-167.

[22] J.G. Hering, P. Chen, J.A. Wilkie, M. Elimelech, Arsenic removal for drinking water during coagulation, J. Environ. Eng. 123 (1997) 800-807.

[23] M.M. Benjamin, R.S. Sletten, R.P. Bailey, T. Bennett, Sorption of arsenic by various adsorbents, in: AWWA Inorganic Contaminant Workshop, San Antonio, TX, February, 1998.

[24] S.S. Adham, J.G. Jacangelo, J.M. Laine, Characteristics and costs of MF and UF plants, J. Am. Water Works Assoc. 88 (1996) 22-31.
[25] P. Brandhuber, G. Amy, Arsenic removal by a charged ultrafiltration membrane-influence of membrane operating conditions and water quality on arsenic rejection, Desalination 140 (2001) 1-14.

[26] Y.J. Chang, M.M. Benjamin, Iron oxide adsorption and UF to remove NOM and control fouling, J. Am. Water Works Assoc. 88 (1996) 74 88.

[27] J.G. Jacangelo, J.M. Laine, K.E. Carns, E.W. Cummings, S.S. Adham, UF with pretreatment for removing DBP precursors, J. Am. Water Works Assoc. 87 (1995) 100-112.

[28] S.S. Adham, V.L. Snoeyink, M.M. Clark, J.L. Bersillon, Predicting and verifying organics removal by PAC in an untrafiltration system, J. Am. Water Works Assoc. 83 (1991) 81-91.

[29] C.F. Lin, Y.J. Huang, O.J. Hao, UF processes for removing humic substances: effect of molecular weight fractions and PAC treatment, Water Res. 33 (1999) 1252-1264.

[30] C.F. Lin, T.Y. Lin, O.J. Hao, Effect of humic substance characteristics on UF performance, Water Res. 34 (2000) 1097-1106.

[31] R.S. Juang, R.C. Shiau, Metal removal from aqueous solutions using chitosan-enhanced membrane filtration, J. Membr. Sci. 165 (2000) 159-167.

[32] T. Hung, C. Kuo, W. Jeng, Characterization of dissolved organic carbon and humic substances in the well water of the blackfoot disease area in Taiwan, Toxicol. Environ. Chem. 46 (1994) 127-134.

[33] R.A.A. Muzzarelli, R. Rocchetti, Determination of the degree of acetylation of chitosans by first derivative ultraviolet spectrophotometry, Carbohydr. Polym. 5 (1985) 461.

[34] C. Jucker, M.M. Clark, Adsorption of aquatic humic substances on hydrophobic ultrafiltration membranes, J. Membr. Sci. 97 (1994) $37-$ 52.

[35] A. Maartens, P. Swart, E.P. Jacobs, Humic membrane foulants in natural brown water: characterization and removal, Desalination 115 (1998) 215-227.

[36] C.F. Lin, S.H. Liu, O.J. Hao, Effect of functional groups of humic substances on UF performance, Water Res. 35 (2001) 2395-2402.

[37] R. Maruca, B.J. Suder, J.P. Wightman, Interaction of heavy metals with chitin and chitosan. III. Chromium, J. Appl. Polym. Sci. 27 (1982) 4827-4837.

[38] J.R. Deans, B.G. Dixon, Uptake of $\mathrm{Pb}^{2+}$ and $\mathrm{Cu}^{2+}$ by novel biopolymers, Water Res. 26 (1992) 469-472.

[39] G.L. Rorrerm, T. Hisen, J.D. Way, Synthesis of porous-magnetic chitosan beads for removal of cadmium ions from waste water, Ind. Eng. Chem. Res. 32 (1993) 2170-2178.

[40] J. Cho, G. Amy, J. Pellegrino, Membrane filtration of natural organic matter: factors and mechanisms affecting rejection and flux decline with charged untrafiltration (UF), J. Membr. Sci. 164 (2000) 89-110.

[41] L. Fan, J.L. Harries, F.A. Roddick, N.A. Booker, Influence of the characteristics of natural organic matter on the fouling of microfiltration, Water Res. 35 (2001) 4455-4463. 